\title{
O Aluno Surdo na Escola Regular: Imagem e Ação do Professor ${ }^{1}$
}

\author{
Angélica Bronzatto de Paiva e Silva² \\ Maria Cristina da Cunha Pereira \\ Universidade de Campinas
}

\begin{abstract}
RESUMO - Com o objetivo de conhecer a imagem que professores de escola regular têm da surdez e do aluno surdo, bem como a influência desta imagem na sua prática pedagógica, procedeu-se à análise de entrevistas e observações em sala de aula de sete professoras do Ensino Fundamental regular, que têm aluno surdo na classe. A interpretação dos dados fundamentou-se na Análise de Conteúdo, proposta por Bardin (1977), tendo sido estabelecidas as seguintes categorias temáticas: intelectual, comportamental, aprendizagem e linguagem. A análise dos dados evidenciou que a dificuldade de linguagem da criança surda leva, muitas vezes, o professor a construir uma imagem equivocada do aluno surdo a qual se reflete nas suas ações em relação às crianças. Assim, embora considerem os alunos inteligentes, bem comportados e com potencial para aprendizagem, todas as professoras pareciam tratar os alunos como tendo muita dificuldade para acompanhar o processo escolar.
\end{abstract}

Palavras-chave: surdez; imagem (Psicologia); surdos-educação.

\section{The Deaf Student in a Non-Specialized School: Theacher's Perception and Behavior}

\begin{abstract}
With the objective of understanding the image that teachers of regular (non-specialized) schools make about deafness and deaf students, as well as the influence of this image in the teaching process, it was performed a series of interviews and observations in the classroom of seven teachers of regular primary school, in which a deaf student is present. The analysis of data was based on the Content Analysis, proposed by Bardin (1977), in which the following thematic categories have been established: intellectual, behavior, learning and language. The analysis of the data indicated that the language difficult of the deaf child leads, in many cases, to the building by the teacher of an incorrect image of the deaf student, which is reflected in the teacher's behavior towards these students. Even though the students are considered to have good learning skills, good behavior and, good potential for learning, all the teachers observed seem to treat the deaf student as having a lot of difficulties to follow the school curriculum.
\end{abstract}

Key words: deafness; image (Psychology); deaf-education.

Este estudo teve como origem a atuação de uma psicóloga que desenvolve um trabalho de orientação destinado a pais de crianças surdas que frequientam escola regular e recebem atendimento especializado no Centro de Estudos e Pesquisas em Reabilitação (Cepre - Unicamp).

No trabalho realizado com as famílias de crianças surdas, as mães queixam-se de que a inclusão não vem ocorrendo como desejariam. Seus filhos têm mais dificuldades para aprender, sobretudo em função da falta de preparo especializado dos professores. $\mathrm{O}$ fato de o professor não estar devidamente preparado para receber o aluno surdo é realidade, e acontece com a maioria dos professores de escola regular. Assim, quando o professor recebe esse aluno, muitas vezes exibe idéias preconcebidas ou concepções equivocadas a respeito da surdez, muitas vezes atribuindo ao aluno imagens depreciativas.

Essas imagens se refletem na própria postura do professor frente a suas ações em relação às crianças. São justamente

1. Este estudo é baseado na dissertação de mestrado da primeira autora, sob a orientação da segunda, apresentada no mestrado em Desenvolvimento Humano e Educação da Faculdade de Educação da Unicamp - Campinas - S.P.

2. Endereço: Cepre (Centro de Estudos e Pesquisas em Reabilitação - Prof Dr. Gabriel Porto) FCM - Unicamp. Av. Adolfo Lutz s/n, Cidade Universitária, Campinas. CEP:13084-880. E-mail: cepre@ fcm.unicamp.br / arbps@uol.com.br estas ações que as mães relatavam como queixas no atendimento em grupo realizado pelo Setor de Psicologia, pedindo orientações tanto para ela como para o professor. Foi neste cenário, de ansiedade e angústia das mães, de discussão destas dificuldades com os profissionais do Programa de Apoio à Escolaridade, que se deu início ao trabalho de busca de dados junto aos professores da escola comum, na tentativa de se definir qual a imagem que estes profissionais têm do aluno surdo, da surdez e do processo ensino-aprendizagem, analisando-se, assim, a influência desta imagem na prática pedagógica.

Para conceituar imagem, recorreu-se a trabalhos da Psicologia Social, mais especificamente às idéias de Serge Moscovici. Para Moscovici (1978), a imagem faz parte das representações sociais que subjazem aos nossos atos e nos tornam comuns.

Ao longo de sua obra, Moscovici (1978) faz uma diferença entre imagem e representação social. A imagem é vista como passiva, apreendida de forma reflexa, na consciência individual ou coletiva de um objeto, de um feixe de idéias que lhe é exterior. A representação, por outro lado, deve ser encarada de um modo ativo, pois seu papel consiste em modelar o que é dado do exterior, na medida em que os indivíduos e os grupos se relacionam de preferência com os objetos, os atos e as situações são constituídos por miríades 
de interações sociais. Em outras palavras, a representação social é uma modalidade de conhecimento particular que tem por função a elaboração de comportamentos e a comunicação entre os indivíduos.

Embora Moscovici (1978) faça uma diferença entre imagem e representação social, ele admite que imagem é utilizada para designar uma organização mais complexa ou mais coerente de juízos de valor ou de avaliação. É concebida como reflexo interno de uma realidade externa, cópia fiel no espírito do que se encontra fora dele, sendo assim uma reprodução passiva de um dado imediato. O autor considera que o indivíduo carrega em sua memória uma coleção de imagens do mundo sob seus diferentes aspectos; é como se essas imagens fossem espécies de "sensações mentais", de impressões que os objetos e as pessoas deixam em nosso cérebro.

O termo imagem será utilizado no decorrer deste trabalho para se referir ao resultado das representações sociais que os sujeitos constroem no contato com os objetos, com as pessoas e com as situações vivenciadas no mundo.

No convívio social e escolar, os sujeitos interagem com base na imagem que fazem de si e do outro. Esta imagem, que se faz das pessoas e mesmo das coisas, não se processa em um vácuo cultural, mas em uma sociedade, com suas tradições, influências históricas e condicionamentos econômicos.

$\mathrm{Na}$ literatura, observam-se concepções diferentes de surdez, as quais parecem ser resultado de duas imagens distintas de surdez e de surdos (Skliar, 1997).

Na concepção clínico-terapêutica de surdez, os surdos são vistos como tendo uma deficiência, a qual deve ser curada para que eles possam se aproximar do normal, o ouvinte. Para isso, os surdos são submetidos a um trabalho de habilitação e/ou reabilitação, visando desenvolver suas habilidades auditivas, bem como a aquisição da linguagem oral.

$\mathrm{Na}$ concepção sócio-antropológica, por outro lado, os surdos são vistos como tendo um acesso diferente ao mundo, o que implica em diferenças em relação aos ouvintes. Pelo fato de não ouvirem, os surdos constituem seu conhecimento de mundo através do canal visual-gestual, adquirem a língua de sinais sem dificuldade e esta vai possibilitar o desenvolvimento tanto dos aspectos cognitivos, como sócio-emocionais, e lingüísticos. O presente estudo investigou a imagem que professores têm de seus alunos surdos.

\section{Método}

\section{Sujeitos}

Foram escolhidas sete professoras do Ensino Fundamental que lecionam em escolas municipais ou estaduais do município ou da região de Campinas, as quais tivessem, no momento da coleta de dados, pelo menos um aluno surdo freqüentando e recebendo apoio à escolaridade no Centro de Estudos e Pesquisas em Reabilitação (CEPRE) da Universidade de Campinas.

\section{Procedimentos}

Os dados foram obtidos por meio de observações e entrevistas semi-estruturadas com as professoras, entre março e abril de 1998. Os tópicos, que poderiam ser relatados naturalmente pelas professoras durante a entrevista ou abordados pela entrevistadora, foram:

1. Frequiência com que o professor tem aluno surdo na sala de aula;

2. Visão a respeito de ter um aluno surdo;

3. Conhecimento de outras pessoas surdas;

4. Concepção da professora em relação à: inteligência, integração, linguagem, personalidade e aprendizagem da pessoa surda;

5. Opinião a respeito dos recursos necessários para o professor atender um aluno surdo.

\section{Observação direta da interação professora-aluno surdo}

Inicialmente, foram realizadas três observações de alunos diferentes em suas respectivas salas de aulas, utilizando-se a técnica do registro contínuo.

A partir deste registro, definiu-se observar a relação da professora com a classe como um todo e a relação da professora com o aluno surdo nos seguintes aspectos:

1. Instrução e condução das atividades;

2. comportamento do aluno no decorrer da aula;

3. relação do aluno surdo com os colegas, e vice-versa.

Foram realizadas três observações, uma no primeiro semestre e duas no segundo semestre. Cada observação teve duração de $1 \mathrm{~h}$, aproximadamente.

O presente trabalho foi desenvolvido se utilizando o método de pesquisa qualitativa.

No tratamento dos dados foi utilizada a técnica de Análise de Conteúdo, proposta por Bardin (1977), na qual a organização da análise é feita em torno de três pólos cronológicos: a pré-análise, a exploração do material, o tratamento dos resultados, a inferência e a interpretação.

A partir do tema escolhido procedeu-se a uma pré-análise das entrevistas transcritas, bem como das observações da sala de aula para estabelecer as categorias temáticas dos dados. A partir desta pré-leitura foram estabelecidas quatro categorias que, juntas, comporiam a imagem que cada professora tem do aluno surdo. Foram elas:

1. aspecto intelectual;

2. aspecto comportamental;

3. aspecto da linguagem;

4. aspecto da aprendizagem.

Com base nas categorias selecionadas, procedeu-se à análise dos dados de cada professora, para depois se agruparem os dados das sete professoras em todas as categorias, possibilitando o estabelecimento da imagem que as mesmas têm do aluno surdo.

\section{Resultados e Discussão}

\section{Aspecto intelectual}

Os dados obtidos na entrevista com as professoras, bem como as observações em sala de aula, apontaram para semelhanças e diferenças em relação ao aspecto intelectual dos surdos, quando comparados com a literatura onde os surdos são vistos como pouco inteligentes, intelectualmente primitivos, com pensamento concreto e confuso (Lane,1992). 
De um modo geral, as professoras consideram seus alunos surdos inteligentes. Algumas afirmam que o aluno surdo é esperto, participante, atento a tudo, até "xereta", realiza a cópia das atividades e faz os exercícios de matemática. Uma das professoras, apesar de afirmar que seu aluno é inteligente, e que sabe colar, pintar e montar, afirma que ele não percebe quando é para fazer lição ou para brincar.

Embora as professoras afirmem que, para elas, a surdez não compromete o desenvolvimento intelectual do aluno, todas fazem menção às dificuldades que o mesmo apresenta nas tarefas, principalmente nas que dizem respeito à linguagem. Uma das professoras, inclusive, declarou que as tarefas que envolvem linguagem ela deixa para a mãe fazer em casa, uma vez que não sabe sinais. Assim, de forma semelhante ao que é relatado na literatura, as professoras observam que seus alunos são inteligentes nas tarefas que não envolvem linguagem. Nestas, embora não verbalizem, as atitudes por elas tomadas revelam uma certa dúvida em relação ao potencial intelectual do aluno surdo.

Ainda que de forma diferente, observou-se nos sujeitos desta pesquisa uma incoerência entre a afirmativa de que os alunos surdos são inteligentes e as posturas que assumem com eles, ajudando-os, deixando-os fazer o que quiserem ou copiando. Ao mesmo tempo em que afirmam que o aluno é inteligente, agem como se ele não o fosse. Assim, enquanto fala "você sabe", a professora age como se ele não soubesse.

Algumas professoras, talvez na tentativa de mostrar que o aluno é inteligente, o ajudam de alguma forma, facilitando a atividade, respondendo por ele, aceitando qualquer resposta ou mesmo deixando-o copiar. Na medida em que a professora ajuda o aluno a resolver suas dificuldades, ela cria neste a imagem de inteligente, o que resulta, muitas vezes, em uma imagem idealizada. $\mathrm{Na}$ imagem idealizada desconsideram-se as dificuldades, criando-se uma ilusão que pode ser tão pesada para o aluno quanto da imagem estigmatizada.

$\mathrm{O}$ fato de considerar o aluno surdo inteligente pode, por outro lado, ser entendido como este não necessitando de nenhuma atenção especial, quase como se, sendo inteligente, o professor não precisa se preocupar com ele, já que pode ser tratado como os demais, sem diferença.

\section{Aspecto comportamental}

Quanto ao aspecto comportamental, a aplicação de avaliações psicológicas em surdos levou muitos autores a atribuírem traços afetivos comuns aos surdos, como imaturidade, agressividade, impulsividade, irritabilidade, teimosia, serem explosivos, com personalidade pouca desenvolvida (Lane, 1992; Souza, 1986).

Embora as pessoas surdas, como as ouvintes, possam ser nervosas, facilmente irritáveis, explosivas, tais características não podem ser atribuídas à surdez, mas muitas vezes às dificuldades em relação à compreensão e ao uso de uma língua partilhada na família e na comunidade.

A análise dos dados das sete professoras, neste estudo, evidenciou:

Em primeiro lugar, talvez por desconhecerem o que diz a literatura sobre surdos e por serem professoras, todas atribuíram ao termo comportamento o sentido de disciplina.
Assim, passaram a comentar sobre a disciplina dos alunos surdos na sala de aula.

Tanto nos relatos como nas observações das professoras nas salas de aula, duas imagens puderam ser apreendidas no que se refere à relação comportamento/surdez. Assim, para algumas professoras, a surdez não tem relação, não interfere e nem influencia o comportamento do aluno, enquanto que, para outras, a surdez interfere no comportamento na sala de aula.

As professoras que acham que a surdez não interfere no comportamento dos alunos afirmam que tratam o aluno surdo igual aos demais. A observação na sala de aula, no entanto, mostrou que as professoras são muito mais tolerantes com o aluno surdo do que com os demais, permitindo que ele levante, ande pela sala e incomode o outro. Mesmo considerando-o igual aos outros, agem como se não o fossem.

As professoras que parecem atribuir as alterações de comportamento à surdez referem comportamentos de nervosismo, de irritação, de agitação, de mexer em tudo, de cutucar os colegas que elas atribuem à não compreensão do aluno sobre o que acontece na classe. No entanto, é interessante notar que, ao criticarem os comportamentos dos alunos, as professoras fazem uso de diminutivos, como "um pouquinho", ou seja, um pouquinho nervoso, um pouquinho rebelde, parecendo, assim, amenizar as suas críticas.

\section{Aspecto da aprendizagem}

Quanto ao aspecto da aprendizagem, a literatura refere que as maiores dificuldades dos surdos, principalmente dos filhos de pais ouvintes, dizem respeito às atividades que envolvem a compreensão e uso da linguagem oral e/ou escrita (Fernandes, 1990). Embora muitos surdos consigam se comunicar oralmente e por escrito, a grande maioria não ultrapassa o nível de codificação e de decodificação das mensagens, muitas vezes sem atribuir um sentido ao "ouvido" e ao lido (Souza \& Mendes,1987). Tal fato compromete a aprendizagem do aluno surdo em todas as disciplinas.

Esta percepção parece estar subjacente aos depoimentos das professoras, informantes desta pesquisa. De um modo geral todas consideram que seus alunos surdos apresentam condições de ter uma aprendizagem normal. Algumas afirmam que a aprendizagem no aluno surdo é normal, ilimitada, mas acontece de maneira diferente e outras afirmam que a aprendizagem dos alunos surdos é normal porque há alunos ouvintes com mais dificuldades que eles. A implicação de uma ou de outra posição é a baixa expectativa das professoras em relação à aprendizagem do aluno surdo.

Quando algumas professoras mencionam que a aprendizagem é diferente, parecem se referir ao fato de acontecer de maneira mais lenta e quando referem que há alunos ouvintes com mais dificuldades, parecem comparar os alunos surdos aos alunos com dificuldades de aprendizagem.

Apesar da imagem de que a aprendizagem do aluno surdo é normal, muitas acabam admitindo que o seu aluno surdo não está aprendendo. Para justificar as dificuldades de aprendizagem dos alunos, algumas professoras mencionam o seu despreparo (da professora), a quantidade de alunos na sala de aula, a falta de assessoria, a necessidade do aluno surdo ter um acompanhamento à parte, os problemas do 
sistema educacional, inclusive a maneira como está acontecendo a inclusão, os problemas de comportamento do aluno e o fato do aluno surdo não ouvir e não falar. Ao justificar as dificuldades dos alunos surdos, algumas professoras se mostram preocupadas, angustiadas e ansiosas, enquanto outras parecem se isentar de qualquer responsabilidade sobre a aprendizagem do aluno surdo.

Com base nos dados obtidos pode-se constatar que existe por parte das professoras uma predisposição maior ou menor em aceitar o aluno surdo. No entanto, como não se sentem preparadas para ensiná-los, algumas chegam mesmo a considerar que para o aluno surdo a cópia é uma forma de aprendizagem.

A maioria das professoras relacionou as dificuldades de aprendizagem do aluno surdo com a falta de linguagem. Neste caso, algumas professoras se responsabilizavam por não saber a língua de sinais e outras atribuíam a dificuldade do aluno ao fato de não estar usando o aparelho de amplificação sonora e conseqüentemente ouvindo e falando menos.

Embora afirmem que o aluno surdo não apresenta problemas de aprendizagem, depreende-se do discurso das professoras a imagem de limitação do aluno, o que parece provocar compaixão em algumas.

\section{Aspecto da linguagem}

Em relação ao aspecto da linguagem, o que se constata na literatura é que esta tem um papel decisivo na formação dos processos mentais da criança, sendo um fator de vital importância para o desenvolvimento de aspectos cognitivos, emocionais e sociais (Vygotsky, 1993).

A preferência por uma língua processada pela modalidade oral/aural ou visual/gestual na educação de surdos está estreitamente vinculada à concepção de surdez que se tem: a clínico-terapêutica (surdez como deficiência) e a sócioantropológica (surdez como diferença).

$\mathrm{Na}$ análise de dados das sete professoras, observou-se que, ainda que se declarassem pouco conhecedoras da surdez, todas revelaram sensibilidade ao notar que a grande dificuldade do aluno surdo está na linguagem.

As professoras que enfatizaram a necessidade do surdo se comunicar oralmente pareciam ter a imagem de que cabe ao aluno surdo se aproximar do ouvinte, inclusive fazendo uso da mesma língua. Uma das professoras chegou mesmo a verbalizar que não era a professora que tinha que se adequar às dificuldades do aluno, mas o aluno surdo que tinha que se adaptar à classe, ou seja, não é a professora que tem que aprender a língua de sinais, mas é a criança surda que tem que usar a linguagem oral. Esta visão é muito próxima a da clínico-terapêutica, que enfatiza o uso do aparelho auditivo e o desenvolvimento da linguagem oral, visando a integração da criança surda à comunidade de ouvintes.

Por outro lado, embora façam referência à importância da língua de sinais, as professoras entrevistadas revelaram pouco conhecimento sobre a mesma, o que pode ser constatado na forma como se referiram à mesma como uma língua universal, um código como o Braille, o alfabeto manual, sinais, gestos, mímica.

$\mathrm{O}$ direito do aluno surdo à educação através da língua de sinais está assegurado na Declaração de Salamanca, no artigo 19, artigo este não incorporado nos documentos que regulam a inclusão do aluno surdo no sistema regular de ensino em nosso país. Assim, o que se vê, na prática, são professores tentando se comunicar com os alunos surdos de qualquer jeito, sem mesmo acreditarem na efetividade de tal procedimento.

\section{Conclusão}

Concluindo a análise das entrevistas de todas as professoras fica evidente que, embora façam um discurso de que os alunos surdos têm todas as condições de serem incluídos porque são inteligentes, aprendem, se comportam bem; na prática, eles são tratados como excluídos, pois se exige menos do aluno surdo e se tolera muito mais comportamentos e atitudes deles diferentemente do que a professora faz com os outros alunos. Assim, ainda que pareçam defender uma possibilidade de inclusão dos alunos surdos, na prática, a atitude das professoras em relação ao aluno surdo é de exclusão.

Em relação à imagem que têm do aluno surdo, as atitudes das professoras deixam transparecer a imagem de que o aluno surdo é menos capaz que o ouvinte, apesar do discurso ser outro.

\section{Referências}

Bardin, L. (1977). Análise de conteúdo. Lisboa: Edições 70.

Fernandes, E. (1990). Problemas Lingüísticos e Cognitivos do Surdo. Rio de Janeiro: Agir.

Lane, H. (1992). A máscara da benevolência: a comunidade surda amordaçada. Lisboa: Instituto Piaget.

Ministério da Educação e do Desporto (1994). Declaração de Salamanca sobre princípios, política e prática em educação especial. (art.19).

Moscovici, S. (1978). A representação social da psicanálise. Rio de Janeiro: Zahar.

Silva, A.B.P. (2000). O aluno surdo na escola regular: imagem e ação do professor. Dissertação de Mestrado, Faculdade Educação da Unicamp, Campinas, S.P.

Skliar, C. (1997). Uma perspectiva sócio-histórica sobre a psicologia e a educação dos surdos. Em:C. Skliar (org.), Educação e exclusão: abordagens sócio-antropológicas em educação especial. (pp. 105-153). Porto Alegre: Mediação.

Souza, R.M. (1986). Contribuição ao estudo de personalidade do adolescente surdo através do T.P.C. de Max Pfister. Dissertação de Mestrado, Instituto de Psicologia da Puccamp, Campinas, S.P.

Souza, R.M. \& Mendes, I.R.(1987). Língua de Sinais e sua influência na educação. Estudos de Psicologia, 4 (1), 35-51.

Vygotsky, L.S. (1993). Pensamento e Linguagem. São Paulo: Martins Fontes.

Recebido em 05.10.2002

Primeira decisão editorial em 07.02.2003

Versão final em 13.06.2003

Aceito em 01.07.2003 